\title{
A Study on Currency Anchor Effect of Chinese Yuan
}

\author{
Zihao Li \\ Department of Finance, College of Economics, Jinan University, Guangzhou, China \\ Email: kiehoelee@foxmail.com
}

How to cite this paper: Li, Z. H. (2020). A Study on Currency Anchor Effect of Chinese Yuan. Modern Economy, 11, 261-272. https://doi.org/10.4236/me.2020.112023

Received: December 19, 2019

Accepted: February 2, 2020

Published: February 5, 2020

Copyright $\odot 2020$ by author(s) and Scientific Research Publishing Inc. This work is licensed under the Creative Commons Attribution International License (CC BY 4.0).

http://creativecommons.org/licenses/by/4.0/

\begin{abstract}
The growing importance of China in the world economy has raised the questsion: Can its national currency, the Chinese Yuan (CNY), become a major international currency? This paper examines whether the Chinese Yuan (CNY) has substituted the US dollar (USD) as the major anchor currency in the implicit currency baskets of some economies. A SVAR approach has been adopted to study the currency anchor effect of nine developing economies as well as G3 economies. The results show that in the aftermath of the global financial crisis, the exchange rate fluctuation of CNY imposes increasingly strengthening impacts on other currencies, while the exchange rate fluctuation of USD imposes generally weakening impacts, leading to the fact that the CNY anchor effect is becoming stronger than the USD.
\end{abstract}

\section{Keywords}

Currency Anchor, CNY, SVAR Model

\section{Introduction}

In December 2015, the International Monetary Fund officially announced that it has approved the entry of CNY into the SDR basket. This implicates the growing importance of CNY in the international monetary system. Recently, China's influence over the world's major economies is expanding. CNY offshore trading centers have been set up across the world. A large amount of CNY have been in circulation abroad. The introduction and implementation of the Belt and Road Initiatives also provide an opportunity for CNY to be pegged by other currencies.

The basic purpose of currency is to reduce transaction costs and currency anchor is aimed to safeguard the value of the currency of sovereign nations (Mckinnon, 1963; Mundell, 1961). While the academic community has not given 
a clear definition of currency anchor for the time being, it is commonly accepted that currency anchors fall into the following three categories. The first is the fixed currency anchor, which refers to the peg of a country's currency to one or a basket of goods. The second is the floating currency anchor, which refers to the targeting of monetary policy to money supply targets, inflation targets etc. And the third category is the basic currency anchor, which refers to the pegging to another country's currency in order to manage its own monetary policy. It is argued that currency anchor is a monetary policy objective (Bordo \& Schwartz, 1999) and that currency anchors are instruments or target variables used by policy makers to manage the floating level of the national currency (Mishkin, 2015).

Currency anchors can be divided into external anchors and internal anchors in accordance with the stability of the external value of a country's currency or the stability of internal value (Mundell, 2000). The currency anchor discussed in this paper is focused on the external anchor, which means a currency seeks to stabilize against another currency or baskets of currencies. In other words, that currency pegs the currency or baskets of currencies as its currency anchor. The role of an external anchor lies in its ability to reduce transaction costs in world trade and financial transactions. Under current international monetary system, many developing countries often choose one or a basket of major international currencies as their currency anchors in order to maintain the exchange rate stability of their currencies. External currency anchors can also be divided into the implicit anchor and dominant anchor, the former of which means undeclared by monetary authorities. And the latter is officially declared. In perspectives of regional monetary cooperation, the implicit anchor is the equilibrium of monetary competition, and the dominant anchor is the product of official policy coordination.

The currency anchor discussed in this paper focuses on the target variable monetary policy pegged to in order to safeguard the value of currencies of sovereign nations. Correspondingly, the currency anchor effect refers to the role of a country's currency as a currency anchor. That is, whether one currency can become the anchor of another currency, changes of a currency's exchange rate's impact on another exchange rate, or the extent of a currency pegged to another.

\section{Modeling: A SVAR Approach}

\subsection{Variable Selection and Modeling}

Considering Frankel and Wei regression model (Frankel \& Wei, 1994) with the movements in the CNY included on the right-hand side:

$$
\ln \mathrm{CON}_{t}=\varphi_{0}+\varphi_{1} \ln \mathrm{JPY}_{t}+\varphi_{2} \ln \mathrm{EUR}_{t}+\varphi_{3} \ln \mathrm{RMB}_{t}+\varphi_{4} \ln \mathrm{USD}_{t}+\mu_{t} .
$$

In this model, $\ln \mathrm{CON}_{t}$ represents a logarithmic form of the nominal exchange rate of an economy's currency during $t$ period. Similarly, $\ln \mathrm{JPY}_{t}, \ln \mathrm{EUR}_{t}, \ln \mathrm{RMB}_{t}, \ln \mathrm{USD}_{t}$ represents that of JPY, EUR, CNY and USD. Considering comparability, this article draws on Frankel and Wei regression model, using Swiss Franc as an external valuation standard to measure the 
movement of the nominal exchange rate of other currencies. That means the nominal exchange rates of those currencies are expressed as the Swiss Franc price.

Taking into account the interaction between exchange rates, this article adopts the SVAR approach in order to analyze the relationship between the five exchange rate variables in Equation (2.1). The SVAR model actually refers to the structural form of VAR model. VAR model does not give the exact form of the current correlation between variables, which means the right hand side of the model does not contain the endogenous variables of the current period. These current correlations are hidden in the relevant structure of the error terms, which cannot be explained. However, SVAR model, on the other hand, contains the current relationship between variables in the model, making it possible to explain.

When analyzing SVAR model, it is often not to analyze the changes in one variable on another. Instead, impulse response function and variance decomposition are standard analyzing techniques.

Impulse response function provides the dynamic of one exchange rate when structural shocks of other currencies are given. Based on impulse response analysis, it is possible to evaluate the relative importance between USD, CNY, EUR and JPY by analyzing the contribution rate of USD, CNY, EUR and JPY.

Hereby in this article, the SVAR model of 5 variables is established as follows:

$$
B_{0} y_{t}=\Gamma_{0}+\Gamma_{1} y_{t-1}+\Gamma_{2} y_{t-2}+\cdots+\Gamma_{p} y_{t-p}+\mu_{t}, t=1,2, \cdots, T
$$

where the variable and parameter matrix are:

$$
\begin{gathered}
y_{t}=\left[\begin{array}{c}
\ln \mathrm{CON}_{t} \\
\ln \mathrm{JPY}_{t} \\
\ln \mathrm{EUR}_{t} \\
\ln \mathrm{RMB}_{t} \\
\ln \mathrm{USD}_{t}
\end{array}\right], B_{0}=\left[\begin{array}{ccccc}
1 & -b_{12} & -b_{13} & -b_{14} & -b_{15} \\
-b_{21} & 1 & -b_{23} & -b_{24} & -b_{25} \\
-b_{31} & -b_{32} & 1 & -b_{34} & -b_{35} \\
-b_{41} & -b_{42} & -b_{43} & 1 & -b_{45} \\
-b_{51} & -b_{52} & -b_{53} & -b_{54} & 1
\end{array}\right], \Gamma_{0}=\left[\begin{array}{l}
\gamma_{10} \\
\gamma_{20} \\
\gamma_{30} \\
\gamma_{40} \\
\gamma_{50}
\end{array}\right] \\
\Gamma_{i}=\left[\begin{array}{lllll}
\gamma_{11}^{(i)} & \gamma_{12}^{(i)} & \gamma_{13}^{(i)} & \gamma_{14}^{(i)} & \gamma_{15}^{(i)} \\
\gamma_{21}^{(i)} & \gamma_{22}^{(i)} & \gamma_{23}^{(i)} & \gamma_{24}^{(i)} & \gamma_{25}^{(i)} \\
\gamma_{31}^{(i)} & \gamma_{32}^{(i)} & \gamma_{33}^{(i)} & \gamma_{34}^{(i)} & \gamma_{35}^{(i)} \\
\gamma_{41}^{(i)} & \gamma_{42}^{(i)} & \gamma_{43}^{(i)} & \gamma_{44}^{(i)} & \gamma_{45}^{(i)} \\
\gamma_{51}^{(i)} & \gamma_{52}^{(i)} & \gamma_{53}^{(i)} & \gamma_{54}^{(i)} & \gamma_{55}^{(i)}
\end{array}\right], i=1,2, \cdots, p ; \mu_{t}=\left[\begin{array}{l}
\mu_{1 t} \\
\mu_{2 t} \\
\mu_{3 t} \\
\mu_{4 t} \\
\mu_{5 t}
\end{array}\right]
\end{gathered}
$$

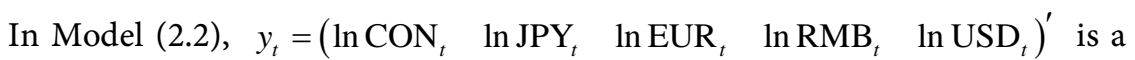
5 -dimensional endogenous variable vector. $\ln \mathrm{CON}_{t}$ is the logarithmic form of the nominal exchange rate of an economy denominated in Swiss Francs during $t$ period. Similarly, $\ln \mathrm{JPY}_{t}, \ln \mathrm{EUR}_{t}, \ln \mathrm{RMB}_{t}, \ln \mathrm{USD}_{t}$ represent that of JPY, EUR, CNY and USD one by one.

In addition, when it comes to $\mathrm{CNY}$ exchange rate movements, the SVAR model of four variables are constructed. At this point,

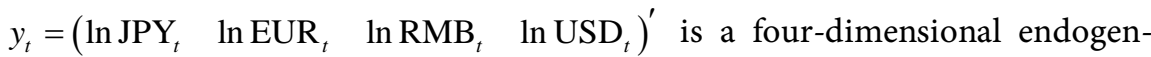
ous variable vector. $B_{0}, \Gamma_{i}$ are both $4 \times 4$ dimensional parameter matrix, $\Gamma_{0}$ is 
a 4-dimensional constant vector and $\mu_{t}$ is a 4-dimensional structural shock vector.

So far, the SVAR model is completed. The rest of this article is data illustration, impulse response analysis and variance decomposition for purpose of assessing CNY currency anchor effect.

\subsection{Data}

Considering research purpose and previous findings, this article selects 13 currencies of countries that trades heavily with China, including Argentine Peso (ARS), Brazilian Real (BRL), Israeli New Shekel (NIS), South African Rand (ZAR), Indonesian Rupee (IDR), Philippine Peso (PHP), Thai Baht (THB), Sri Lankan Rupee (LKR), New Taiwan Dollar (TWD), Japanese Yen (JPY), EURO (EUR), Chinese Yuan (CNY), and US dollar (USD). All data are nominal exchange rate of these currencies with daily frequency, acquired from website of FEB and the European Central Bank.

After the adjustment of holiday factors, 555 observations are in the period from 1 August 2006 to 15 September 2008, while 459 observations in the period from 16 September 2008 to 19 June 2010. In addition, 1342 observations are in the period from 20 June 2010 to 11 August 2015 and 363 observations are in the period from 12 August 2015 to 31 December 2018.

The empirical analysis in this article is carried out in Eviews 9.0.

\section{Results}

\subsection{Impulse Response Analysis}

Impulse response analysis is to analyze the dynamic impact of the system when an error term changes, or when the model is affected by certain structural shocks.

Impose JPY exchange rate structural shocks、 euro-rate structural shocks, CNY exchange rate structural shocks and USD exchange rate structural shocks successively on the SVAR model of 5 endogenous variables and then observe the impulse response function of each structural shock to the changes of each currency over 10 periods. That's the technique used for evaluating the dynamic impact of CNY exchange rate structural shocks and for analyzing currency anchor effect of CNY. Similarly, impose JPY exchange rate structural shocks, euro-rate structural shocks, CNY exchange rate structural shocks and USD exchange rate structural shocks successively on the SVAR model of 4 endogenous variables and then observe the impulse response function of each structural shock to the changes of G3 currency over 10 periods in order to evaluate the dynamic of CNY currency anchor effect. Results are given by the impulse response tables below. Due to space limitation, only part of the impulse response results presented in this paper.

Tables 1-4 show the simplified impulse response trajectory of 12 currencies to USD exchange rate structural shocks, CNY exchange rate structural shocks, eu- 
ro-rate structural shocks and JPY exchange rate structural shocks.

As tables show, during the period from 1 August 2006 to 15 September 2008, in stage 2, Argentine Peso responded 0.0012 unit to one standard USD exchange rate structural shock, in contrast to 0.0021 unit to one standard CNY exchange rate structural shock. In addition, Indonesian Rupee responded 0.0010 unit to one standard USD exchange rate structural shock and 0.0015 unit to one standard CNY exchange rate structural shock in the same stage. Moreover, while Philippine Peso remained silent to one standard USD exchange rate structural shock in stage 2, it responded 0.0015 unit to one standard CNY exchange rate structural shock. Fluctuations in USD significantly affected Argentine Peso, Indonesian Rupee and Philippine Peso, while fluctuations in CNY appeared the same and stronger than USD. As for Brazilian Real, impacts from fluctuations of CNY were evident but impacts from fluctuations of USD were silent. During this period, China maintained high-speed development of economy, so fluctuations of currencies of developing economies stayed closely with fluctuations of CNY in order to deliver stability in currencies for international trade settlements. It is one possible explanation why CNY currency anchor effect exceeds USD currency anchor effect. Then compare CNY with EUR. It can be found that the impacts from fluctuations of CNY on currencies of developing economies are stronger and more stable than that of EUR over the same period. Even impact from fluc

Table 1. Impulse response of USD.

\begin{tabular}{|c|c|c|c|c|c|c|c|c|c|c|c|c|c|}
\hline & $\begin{array}{l}\text { Periods } \\
\text { of time }\end{array}$ & stage & & & Impulse I & espons & e of Dev & eloping $\mathrm{E}$ & conomies & & & $\begin{array}{l}\text { Impulse } \\
\text { Develop }\end{array}$ & $\begin{array}{l}\text { Response of } \\
d \text { Economies }\end{array}$ \\
\hline & & & ARS & BRL & IDR & LKR & NIS & PHP & THB & TWD & ZAR & JPY & EUR USD \\
\hline & & 2 & 0.0012 & & 0.0010 & & & & & & & & \\
\hline & $\begin{array}{c}2006 / 08 / 01- \\
2008 / 9 / 15\end{array}$ & 7 & & & & & & -0.0012 & & & & & \\
\hline & & 8 & 0.0011 & & 0.0012 & & & 0.0013 & & & & & \\
\hline & & 9 & & & & & & 0.0018 & & & & & \\
\hline & & 2 & & & 0.0012 & & & & & & -0.0014 & & \\
\hline & & 4 & & & & 0.0011 & & & 0.0011 & 0.0013 & & & \\
\hline Impulse & & 5 & 0.0012 & 0.0032 & 0.0016 & & & 0.0013 & & & 0.0015 & & 0.0008 \\
\hline $\begin{array}{c}\text { Response } \\
\text { of USD }\end{array}$ & $\begin{array}{c}2008 / 09 / 16- \\
2010 / 6 / 18\end{array}$ & 6 & & & -0.0013 & & & 0.0010 & & & 0.0020 & & \\
\hline & & 7 & & 0.0024 & & & 0.0010 & & & & 0.0015 & & \\
\hline & & 8 & & 0.0019 & & & & & & & & & \\
\hline & & 9 & & & & 0.0010 & & & & & & & 0.0005 \\
\hline & $\begin{array}{c}2010 / 06 / 19- \\
2015 / 8 / 11\end{array}$ & 5 & & & & & & & 0.0006 & & & & \\
\hline & & 2 & & & & & & 0.0007 & & & & & \\
\hline & 2015/08/12- & 6 & & -0.0012 & & & & & & & & & \\
\hline & $2018 / 12 / 31$ & 8 & & -0.0013 & & & & & -0.0005 & -0.0006 & & & \\
\hline & & 9 & & & & & & & & & & -0.0005 & \\
\hline
\end{tabular}


Table 2. Impulse response of CNY.

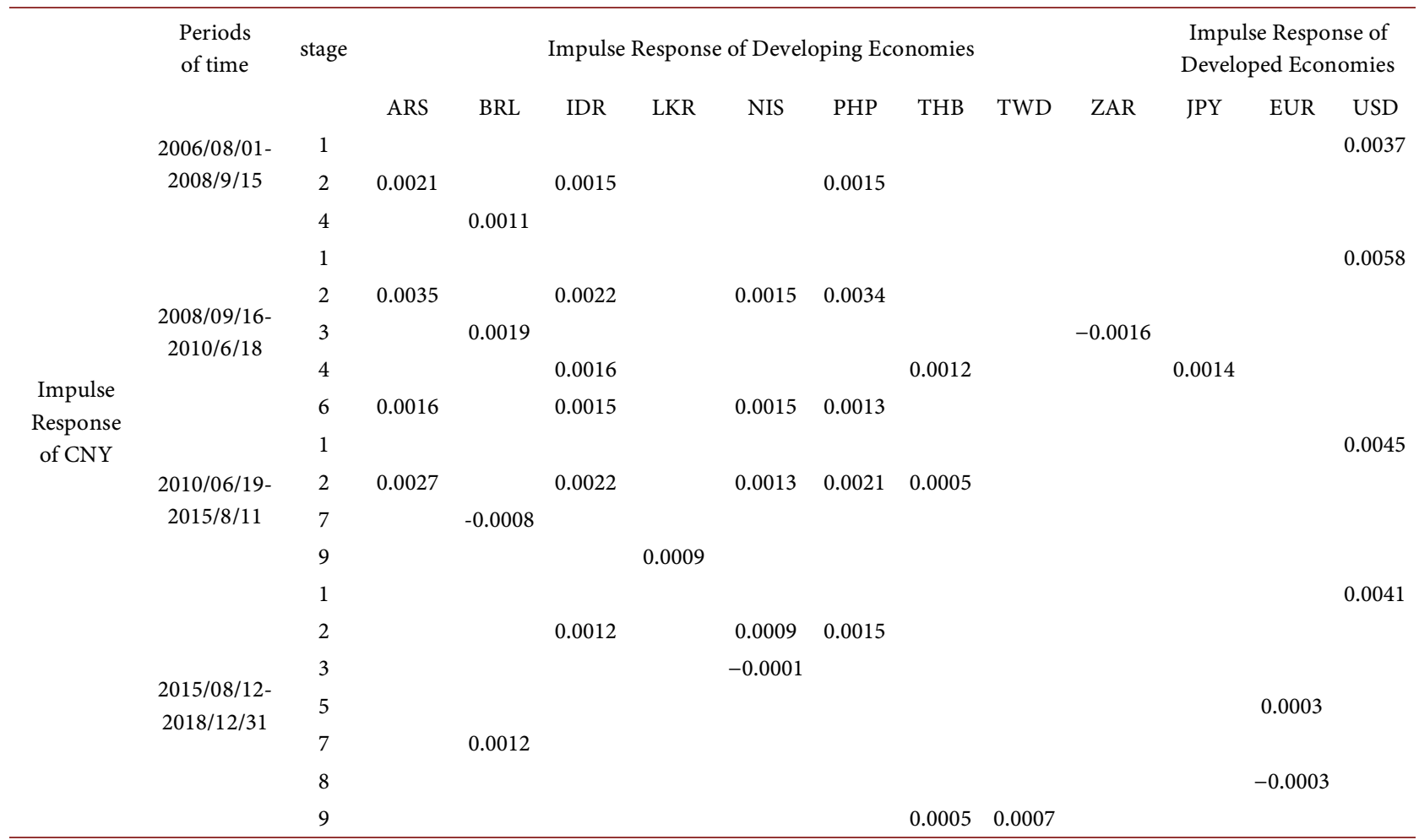

Table 3. Impulse response of EUR.

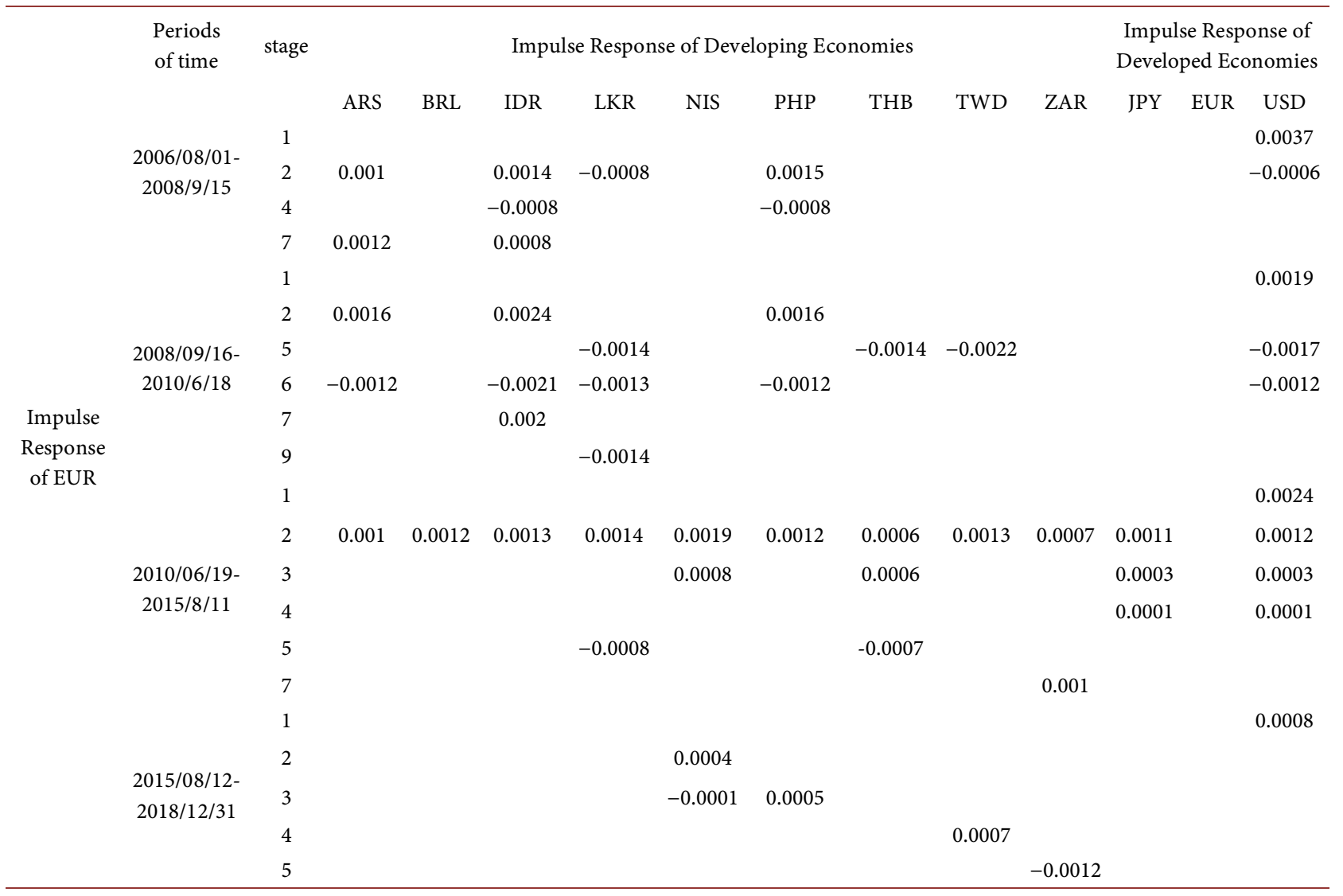


Table 4. Impulse response of JPY.

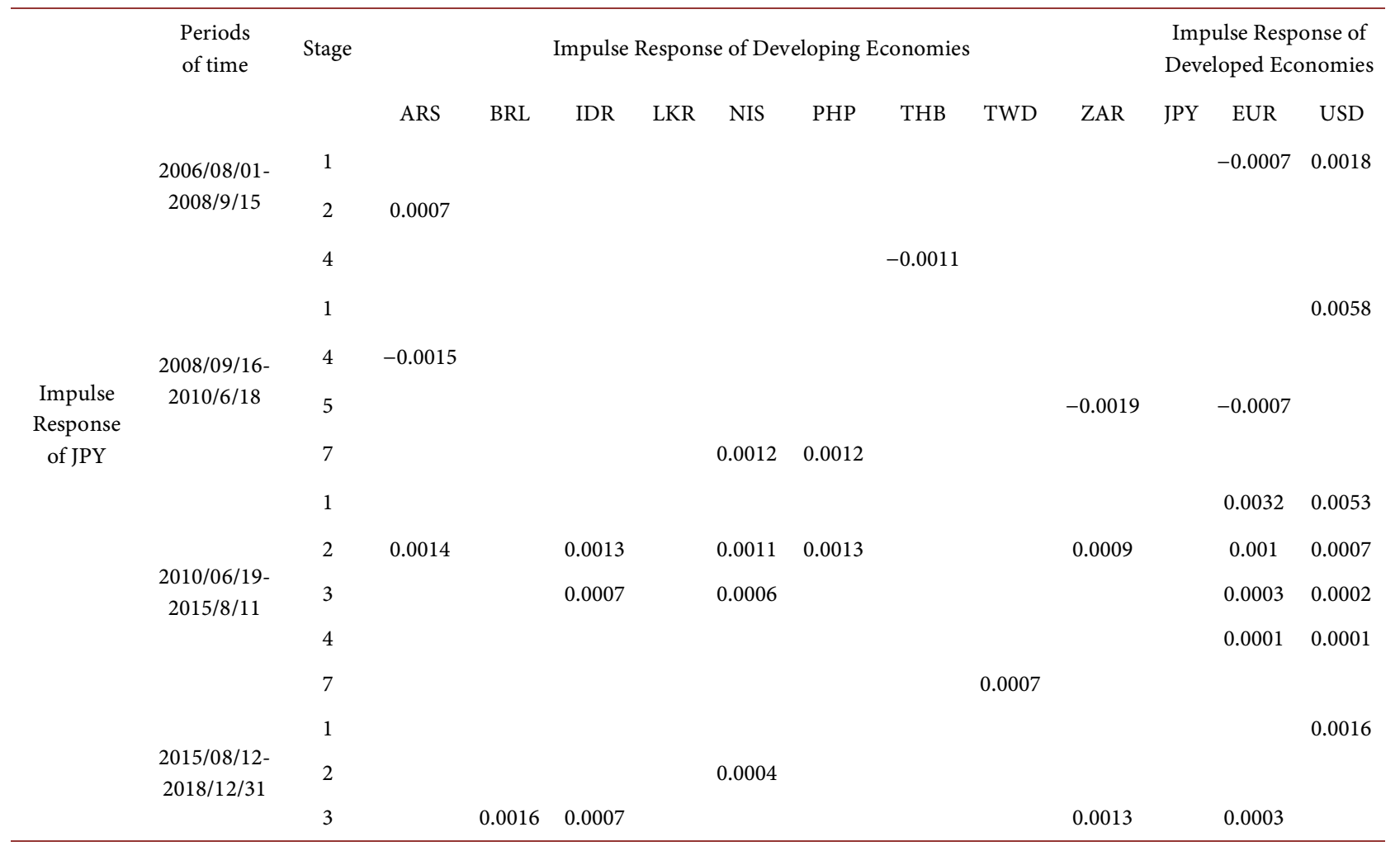

tuations of EUR on Indonesian Rupee and Philippine Peso was huge, but it is unstable. Compare CNY with JPY. Co-movements between currencies of developing economies and CNY are stronger where JPY fluctuations only significantly affect Argentine Peso and Thai Baht and weaker currency anchor effect than that of CNY. In terms of developed economies, impacts from CNY fluctuations on USD were significantly positive and stronger than that of JPY. During this period, China implemented the reform of the CNY exchange rate system. In the meanwhile, China maintained high-speed development of economy and trade contacts with the outside world has been growing over many years, resulting in demands for stable currency anchor to deal with international trade settlements. The CNY currency anchor effect was beginning to emerge.

During 16 September 2008 to 19 June 2010, the impact from USD fluctuations on currencies of developing economies was declining especially on Argentine Peso, Indonesian Rupee, Israeli New Shekel, Philippine Peso, Thai Baht and South African Rand. Nevertheless, influence from CNY fluctuations on these currencies was on the rise, and was about equal or even beyond that of USD. Affected by the global financial crisis, safe-haven assets were in short supply. That China successfully maintained its rapid development in economy during the financial crisis hugely boosted the demands for assets denominated in CNY, thereby enhancing the CNY currency anchor effect. As for developed countries, the euro-rate responded significantly to JPY impulse as well as USD impulse. However, JPY responded significantly to CNY impulse while USD responded signifi- 
cantly to all impulses. Overall, the CNY currency anchor effect was on the rise. However, CNY has returned to the peg to USD since July 2008, making the results of this period less meaningful.

For the period from 20 June 2010 to 11 August 2015, impacts from USD fluctuations on eight currencies of developing economies weakened with the exception of Thai Baht. For some reason, CNY currency anchor effect was significantly stronger than that of USD during this period. For developed economies, EUR kept pegging to JPY and USD and responded significantly to JPY impulse and USD impulse. However, JPY shifted itself to EUR and responded significantly to EUR impulse while USD responded significantly to all impulses. During this period, the reform in China's exchange rate system has been restarted and economic growth in China was still steady after the financial crisis. The CNY currency anchor effect has been further enhanced.

For the period from 12 August 2015 to 31 December 2018, in spite of impacts from USD fluctuations on currencies of developing economies recovered than previous period, impacts from CNY fluctuations were rather stronger, especially on Brazilian Real, Philippine Peso, Thai Baht and Taiwan dollar. It reveals that the CNY currency anchor effect is actually stronger than that of USD. For developed economies, EUR shifted itself pegging to JPY and CNY and responded significantly to JPY impulse as well as CNY impulse. Nevertheless, JPY turned to peg to USD and responded significantly to USD impulse while USD still responded significantly to all impulses.

\subsection{Variance Decomposition}

While Impulse response function is used for observing how the variables in the model react to the impulse over time, variance decomposition is a tool to further evaluate the importance of different structural shocks by analyzing the contribution of each structural shock to the change of endogenous variables. Variance decomposition provides information about relative importance of each random disturbance that affects endogenous variables in SVAR model.

Impose JPY exchange rate structural shocks, euro-rate structural shocks, CNY exchange rate structural shocks and USD exchange rate structural shocks successively on the SVAR model of 5 endogenous variables and then observe the relative contribution of each structural shock to the changes of each currency over 10 periods. That's the technique used for evaluating the relative importance of CNY exchange rate structural shocks and for analyzing relative strength of currency anchor effect of CNY. Similarly, impose JPY exchange rate structural shocks, euro-rate structural shocks, CNY exchange rate structural shocks and USD exchange rate structural shocks successively on the SVAR model of 4 endogenous variables and then observe the relative contribution of each structural shock to the changes of G3 currency over 10 periods in order to evaluate the relative importance of CNY exchange rate structural shocks. Results are given by the variance decomposition tables below. For simplicity, the variance decomposition results presented in this paper do not take into account self-contribution 
rate of each currency.

Table 5 shows the relative contribution rate of the JPY exchange rate structural shocks, euro-rate structural shocks, CNY exchange rate structural shocks and USD exchange rate structural shocks to other currencies' changes.

From 1 August 2006 to 15 September 2008, fluctuations of USD results in contribution disparity to currencies of nine developing economies. Compared with contribution of CNY in the same period, contribution of USD to each currency of developing economies was weaker as reported in Table 5, Indonesian

Table 5. Variance decomposition (self-contribution excluded).

\begin{tabular}{|c|c|c|c|c|c|c|c|c|c|c|c|c|c|c|}
\hline & $\begin{array}{l}\text { Periods } \\
\text { of time }\end{array}$ & stage & & Var & riance $\mathrm{De}$ & ecomposi & ition of $\mathrm{D}$ & evelopin & g Econon & & & $\begin{array}{l}\text { Varianc } \\
\text { of Deve }\end{array}$ & $\begin{array}{l}\text { e Decom } \\
\text { loped Ecc }\end{array}$ & $\begin{array}{l}\text { position } \\
\text { nomies }\end{array}$ \\
\hline \multirow{9}{*}{$\begin{array}{c}\text { Contribution } \\
\text { of USD }\end{array}$} & & & ARS & BRL & IDR & LKR & NIS & PHP & THB & TWD & ZAR & JPY & EUR & USD \\
\hline & $\begin{array}{c}2006 / 08 / 01- \\
2008 / 09 / 15\end{array}$ & 1 & $0 \%$ & $0 \%$ & $0 \%$ & $0 \%$ & $0 \%$ & $0 \%$ & $0 \%$ & $0 \%$ & $0 \%$ & $0 \%$ & $0 \%$ & \\
\hline & & 10 & $32.42 \%$ & $26.52 \%$ & $32.55 \%$ & $1.70 \%$ & $14.56 \%$ & $47.51 \%$ & $9.24 \%$ & $10.20 \%$ & $23.35 \%$ & $3.46 \%$ & $3.20 \%$ & \\
\hline & 2008/09/16- & 1 & $0 \%$ & $0 \%$ & $0 \%$ & $0 \%$ & $0 \%$ & $0 \%$ & $0 \%$ & $0 \%$ & $0 \%$ & $0 \%$ & $0 \%$ & \\
\hline & $2010 / 06 / 19$ & 10 & $9.61 \%$ & $47.34 \%$ & $15.90 \%$ & $26.53 \%$ & $11.90 \%$ & $11.57 \%$ & $21.03 \%$ & $18.05 \%$ & $35.71 \%$ & $31.60 \%$ & $46 \%$ & \\
\hline & $2010 / 06 / 20-$ & 1 & $0 \%$ & $0 \%$ & $0 \%$ & $0 \%$ & $0 \%$ & $0 \%$ & $0 \%$ & $0 \%$ & $0 \%$ & $0 \%$ & $0 \%$ & \\
\hline & $2015 / 08 / 11$ & 10 & $1.13 \%$ & $14.09 \%$ & $6.13 \%$ & $2.79 \%$ & $2.48 \%$ & $1.49 \%$ & $14.03 \%$ & $8.01 \%$ & $19.64 \%$ & $10.92 \%$ & $0.49 \%$ & \\
\hline & $2015 / 08 / 12-$ & 1 & $0 \%$ & $0 \%$ & $0 \%$ & $0 \%$ & $0 \%$ & $0 \%$ & $0 \%$ & $0 \%$ & $0 \%$ & $0 \%$ & $0 \%$ & \\
\hline & $2018 / 12 / 31$ & 10 & $6.10 \%$ & $34.11 \%$ & $13.75 \%$ & $20.27 \%$ & $3.85 \%$ & $22.83 \%$ & $34.98 \%$ & $32.33 \%$ & $14.63 \%$ & $28.93 \%$ & $16.64 \%$ & \\
\hline \multirow{8}{*}{$\begin{array}{c}\text { Contribution } \\
\text { of CNY }\end{array}$} & $2006 / 08 / 01-$ & 1 & $0 \%$ & $0 \%$ & $0 \%$ & $0 \%$ & $0 \%$ & $0 \%$ & $0 \%$ & $0 \%$ & $0 \%$ & $0 \%$ & $0 \%$ & $45.01 \%$ \\
\hline & $2008 / 09 / 15$ & 10 & $35.67 \%$ & $48.03 \%$ & $25.11 \%$ & $7.95 \%$ & $24.37 \%$ & $21.37 \%$ & $16.25 \%$ & $17.35 \%$ & $41.32 \%$ & $90.02 \%$ & $0.50 \%$ & $44.58 \%$ \\
\hline & 2008/09/16- & 1 & $0 \%$ & $0 \%$ & $0 \%$ & $0 \%$ & $0 \%$ & $0 \%$ & $0 \%$ & $0 \%$ & $0 \%$ & $0 \%$ & $0 \%$ & $51.98 \%$ \\
\hline & $2010 / 06 / 19$ & 10 & $55.68 \%$ & $17.48 \%$ & $29.53 \%$ & $19.37 \%$ & $48.43 \%$ & $56.75 \%$ & $28.40 \%$ & $26.17 \%$ & $11.65 \%$ & $44.79 \%$ & $13.72 \%$ & $49.41 \%$ \\
\hline & $2010 / 06 / 20$ & 1 & $0 \%$ & $0 \%$ & $0 \%$ & $0 \%$ & $0 \%$ & $0 \%$ & $0 \%$ & $0 \%$ & $0 \%$ & $0 \%$ & $0 \%$ & $37.58 \%$ \\
\hline & $2015 / 08 / 11$ & 10 & $67.02 \%$ & $17.21 \%$ & $47.72 \%$ & $22.42 \%$ & $21.24 \%$ & $54.83 \%$ & $16.29 \%$ & $4.01 \%$ & $12.53 \%$ & $5.04 \%$ & $0.04 \%$ & $36.16 \%$ \\
\hline & $2015 / 08 / 12$ & 1 & $0 \%$ & $0 \%$ & $0 \%$ & $0 \%$ & $0 \%$ & $0 \%$ & $0 \%$ & $0 \%$ & $0 \%$ & $0 \%$ & $0 \%$ & $83.94 \%$ \\
\hline & $2018 / 12 / 31$ & 10 & $21.02 \%$ & $21.12 \%$ & $49.22 \%$ & $39.64 \%$ & $67.83 \%$ & $53.87 \%$ & $32.05 \%$ & $32.22 \%$ & $26.22 \%$ & $30.29 \%$ & $51.29 \%$ & $82.14 \%$ \\
\hline \multirow{8}{*}{$\begin{array}{l}\text { Contribution } \\
\text { of EUR }\end{array}$} & $2006 / 08 / 01-$ & 1 & $0 \%$ & $0 \%$ & $0 \%$ & $0 \%$ & $0 \%$ & $0 \%$ & $0 \%$ & $0 \%$ & $0 \%$ & $0 \%$ & & $44.35 \%$ \\
\hline & $2008 / 09 / 15$ & 10 & $21.19 \%$ & $18.28 \%$ & $33.58 \%$ & $85.80 \%$ & $24.68 \%$ & $24.17 \%$ & $22.97 \%$ & $71.43 \%$ & $32.04 \%$ & $6.53 \%$ & & $44.83 \%$ \\
\hline & 2008/09/16- & 1 & $0 \%$ & $0 \%$ & $0 \%$ & $0 \%$ & $0 \%$ & $0 \%$ & $0 \%$ & $0 \%$ & $0 \%$ & $0 \%$ & & $4.93 \%$ \\
\hline & $2010 / 06 / 19$ & 10 & $20.12 \%$ & $23.06 \%$ & $39.75 \%$ & $39.70 \%$ & $22.64 \%$ & $21.69 \%$ & $36.91 \%$ & $48.78 \%$ & $12.69 \%$ & $23.61 \%$ & & $11.57 \%$ \\
\hline & $2010 / 06 / 20$ & 1 & $0 \%$ & $0 \%$ & $0 \%$ & $0 \%$ & $0 \%$ & $0 \%$ & $0 \%$ & $0 \%$ & $0 \%$ & $0 \%$ & & $10.97 \%$ \\
\hline & $2015 / 08 / 11$ & 10 & $13.31 \%$ & $35.16 \%$ & $23.04 \%$ & $58.64 \%$ & $55.37 \%$ & $20.66 \%$ & $50.68 \%$ & $64.39 \%$ & $39.14 \%$ & $84.03 \%$ & & $13.45 \%$ \\
\hline & $2015 / 08 / 12-$ & 1 & $0 \%$ & $0 \%$ & $0 \%$ & $0 \%$ & $0 \%$ & $0 \%$ & $0 \%$ & $0 \%$ & $0 \%$ & $0 \%$ & & $2.85 \%$ \\
\hline & $2018 / 12 / 31$ & 10 & $43.73 \%$ & $13.08 \%$ & $10.73 \%$ & $25.17 \%$ & $16.78 \%$ & $12.66 \%$ & $17.72 \%$ & $24.06 \%$ & $29.73 \%$ & $40.78 \%$ & & $4.21 \%$ \\
\hline \multirow{8}{*}{$\begin{array}{c}\text { Contribution } \\
\text { of JPY }\end{array}$} & $2006 / 08 / 01-$ & 1 & $0 \%$ & $0 \%$ & $0 \%$ & $0 \%$ & $0 \%$ & $0 \%$ & $0 \%$ & $0 \%$ & $0 \%$ & & $100 \%$ & $10.64 \%$ \\
\hline & $2008 / 09 / 15$ & 10 & $10.72 \%$ & $7.17 \%$ & $8.76 \%$ & $4.55 \%$ & $36.39 \%$ & $6.94 \%$ & $51.54 \%$ & $1.02 \%$ & $3.29 \%$ & & $96.30 \%$ & $10.59 \%$ \\
\hline & 2008/09/16- & 1 & $0 \%$ & $0 \%$ & $0 \%$ & $0 \%$ & $0 \%$ & $0 \%$ & $0 \%$ & $0 \%$ & $0 \%$ & & $100 \%$ & $43.09 \%$ \\
\hline & $2010 / 06 / 19$ & 10 & $14.59 \%$ & $12.11 \%$ & $14.82 \%$ & $14.40 \%$ & $17.03 \%$ & $9.98 \%$ & $13.66 \%$ & $7 \%$ & $39.95 \%$ & & $40.28 \%$ & $39.02 \%$ \\
\hline & $2010 / 06 / 20-$ & 1 & $0 \%$ & $0 \%$ & $0 \%$ & 5 & $0 \%$ & $0 \%$ & $0 \%$ & $0 \%$ & $0 \%$ & & $100 \%$ & $51.46 \%$ \\
\hline & $2015 / 08 / 11$ & 10 & $18.53 \%$ & $33.53 \%$ & $23.11 \%$ & $16.16 \%$ & $20.91 \%$ & $23.02 \%$ & $19 \%$ & $23.59 \%$ & $28.69 \%$ & & $99.47 \%$ & $50.40 \%$ \\
\hline & $2015 / 08 / 12-$ & 1 & $0 \%$ & $0 \%$ & $0 \%$ & $0 \%$ & $0 \%$ & $0 \%$ & $0 \%$ & $0 \%$ & $0 \%$ & & $100 \%$ & $13.21 \%$ \\
\hline & $2018 / 12 / 31$ & 10 & $29.15 \%$ & $31.69 \%$ & $26.30 \%$ & $14.92 \%$ & $11.54 \%$ & $10.64 \%$ & $15.41 \%$ & $11.39 \%$ & $29.42 \%$ & & $32.07 \%$ & $13.66 \%$ \\
\hline
\end{tabular}


From 1 August 2006 to 15 September 2008, fluctuations of USD results in contribution disparity to currencies of nine developing economies. Compared with contribution of CNY in the same period, contribution of USD to each currency of developing economies was weaker as reported in Table 5, Indonesian rupee and Philippine peso excluded. That indicates exchange rate fluctuations of these developing economies were more affected by exchange rate fluctuations of $\mathrm{CNY}$, and currency anchor effect of CNY surpasses currency anchor effect of USD. Compare CNY with EUR. It can be found that exchange rate of CNY exerts stronger influence on Argentine Peso, Brazilian Real and South African Rand than that of EUR over the same period while similar performance are given to Israel New Shekel. Compare CNY with JPY. Excluding Israeli New Shekel and Thai Baht, CNY currency anchor effect was obviously prevailing over JPY on developing economies. As for developed economies, JPY was essentially pegged to the CNY during this period. While EUR was pegged to JPY, USD was pegged to EUR and JPY, which implicates the currency anchor effect of CNY was superior. In reality, it reveals China's reform in exchange rate system have achieved initial success, that announced it began to transit to managed floating exchange rate based on market force as well as proper regulation. $\mathrm{CNY}$ exchange rate is no longer nailed to USD alone and CNY currency anchor effect is beginning to emerge.

For the period from 16 September 2008 to 19 June 2010, the impact from fluctuations in USD on Argentina Peso, Indonesian Rupee, Israeli New Shekel and the Philippine Peso was declining compared to previous period. Meanwhile, the impact from fluctuations in $\mathrm{CNY}$ on those four currencies was on the rise and exceeded the contribution of USD. In addition, the impact from fluctuations in CNY on Thai Baht and TWD increased and exceeded the contribution of USD. Affected by the global financial crisis, turbulence in international financial market has dealt a blow to US economy and aroused market expectations of continued depreciation of USD. It caused currencies pegging to USD allocated smaller pegging shares on USD to varying degrees. As for developed economies, G3 currencies no longer observe closely sole USD. Contribution of CNY accounting for JPY fluctuations reached for 45\%, which is on top of USD and EUR. Contribution of JPY instead of USD accounting for EUR fluctuations reached for $40 \%$. In a comprehensive sense, CNY currency anchor effect is tending to strengthen. However, affected by the financial crisis, CNY has returned to the peg to USD since July 2008, making the variance decomposition results of the period less significance.

From 20 June 2010 to 11 August 2015, the impact from fluctuations of USD on currencies of nine developing economies was significantly reduced compared to the second period. Compared with contribution of CNY, contribution of USD to each currencies of developing economies was weaker with the exception of TWD and South African Rand. At the same time, the impact from fluctuations of CNY on Argentine Peso, Indonesian Rupee, Sri Lankan Rupee and South African Rand has been further enhanced. As for developed economies, US dollar 
and Chinese Yuan have both significantly reduced their influence on JPY. JPY has shifted to peg closely to EUR, resulting in $84 \%$ of fluctuations from EUR. EUR has adopted a similar strategy, shifting to peg itself closely to JPY. Meanwhile, USD has allocated more shares to JPY than CNY. Contribution rate of CNY has declined. The reform in China's exchange rate system has been restarted at the beginning of this period and the policy of pegging CNY closely to USD since July 2008 has been withdrawn. At the same time, internationalization of CNY has been accelerating as trade contacts of China with other economies roared. Influence of CNY on developing economies has gradually increased, and CNY currency anchor effect has risen steadily.

For the period from 12 August 2015 to 31 December 2018, the impact from USD fluctuations on currencies of nine developing economies was slightly rebounded with the exception of South African Rand, compared to the third period. However, it is lower than the second period. In contrast, currency anchor effect of CNY is stronger than that of USD with the exception of the Brazilian Real and Thai Baht. As for developed economies, contribution of CNY accounting for JPY fluctuations returned to $30 \%$, which was slightly higher than the contribution of USD. Contribution of CNY accounting for EUR fluctuations reached for $51 \%$, which was significantly higher than that of USD of $16 \%$. Moreover, $82 \%$ of USD fluctuations can be explained by CNY exchange rate movement. On August 11 2015, PBOC (Central Bank of China) announced the reform for CNY exchange rate mid-point quotation mechanism. Meanwhile, on December 11 2015, the CNY exchange rate index was released, emphasizing the increasing reference to a basket of currencies. First, these policies effectively promoted China's economic opening-up and accelerated the process of CNY internationalization. Second, the spreading of the European debt crisis, Brexit and IMF's approval of the CNY to join the SDR currency basket, have contributed to the overall deepening of China's Belt and Road Initiatives. Third, trade contacts and investment between China and the outside world triggered the steadily increasing use of CNY in cross-border trade and direct investment. The CNY currency anchor effect is getting stronger and stronger. This is also backed up by the results of impulse response analysis.

\section{Conclusion}

As one of the five SDR basket currencies, it is of great significance to study the impact of CNY on other currencies, namely, the currency anchor effect of CNY, to promote the implementation of the Belt and Road Initiatives and the process of CNY internationalization. This paper adopts a SVAR approach to analyze the currency anchor effect of CNY. Due to the impulse response analysis and variance decomposition of the currencies of nine developing economies and G3 currency, the currency anchor effect of CNY has been verified. The empirical results show that, although there exists regional disparity to CNY currency anchor effect, currency anchor effect of CNY tends to strengthen after the financial crisis and gradually surpass the currency anchor effect of USD, while the cur- 
rency anchor effect of USD tends to weaken after the financial crisis compared to the currency anchor effect of CNY. It shows that the currency anchor effect of CNY is stronger than the currency anchor effect of USD, or coexists side by side with the currency effect of USD.

Some cautions are needed with regard to this method, which is based on the assumptions that: 1) USD only responses to exogenous shocks, 2) CNY only responses to USD fluctuations, 3) EUR only responses to USD and CNY, 4) JPY only responses to USD, CNY and EUR. Those assumptions, which impose constraints of upper triangular matrix, are common in SVAR models in order to solve the problem of over-parameterized. However, there might be the case when those four currencies response to each other. May be by choosing periods of some flexibility of those four currencies or by changing the numeraire currency is the way for future improvement.

\section{Acknowledgements}

The author thanks the anonymous referees for constructive comments on early versions of the paper and is also grateful for the excellent research assistance provided by Jinan University. The views expressed in the paper are those of the author and do not necessarily reflect those of Jinan University and its institutes.

\section{Conflicts of Interest}

The author declares no conflicts of interest regarding the publication of this paper.

\section{References}

Bordo, M. D., \& Schwartz, A. J. (1999). Monetary Policy Regimes and Economic Performance: The Historical Record. Handbook of Macroeconomics, 1, 149-234. https://doi.org/10.1016/S1574-0048(99)01006-X

Frankel, J. A., \& Wei, S. J. (1994). Yen Bloc or Dollar Bloc? Exchange Rate Policies of the East Asian Economies. In T. Ito, \& A. O. Krueger (Eds.), Macroeconomic Linkage: Savings, Exchange Rates, and Capital Flows (pp. 295-333), Chicago: University of Chicago Press.

McKinnon, R I. (1963). Optimum Currency Areas. The American Economic Review, 53, 717-725

Mishkin, F. S. (2015). Economics of Money Banking and Financial Markets (5th ed., pp. 227-243).

Mundell, R. (2000). Currency Areas, Exchange Rate Systems and International Monetary Reform. Journal of Applied Economics, 3, 217-256. https://doi.org/10.1080/15140326.2000.12040550

Mundell, R. A. (1961). A Theory of Optimum Currency Areas. The American Economic Review, 51, 657-665. 